\title{
Bioengineering of Human Artificial Ovary From Cryopreserved Tissue: Optimization of the Follicles Enzymatic Isolation.
}

\section{Jing Chen}

Universitat zu Koln

\section{Evgenia Isachenko}

Universitat zu Koln

\section{Wanxue Wang}

Universitat zu Koln

\section{Xinxin Du}

Universitat zu Koln

\section{Mengying Wang}

Universitat zu Koln

Gohar Rahimi

Universitat zu Koln

Peter Mallmann

Universitat zu Koln

Vladimir Isachenko ( $\sim$ vladimir.isachenko@gmail.com )

Universitat zu Koln https://orcid.org/0000-0002-3674-543X

\section{Research}

Keywords: Artificial ovary, Follicle, Ovarian tissue, Enzymatic isolation, Cryopreservation, Liberase DH, Tumor dissociation enzyme, follicle culture

Posted Date: February 5th, 2021

DOl: https://doi.org/10.21203/rs.3.rs-190433/v1

License: (c) (i) This work is licensed under a Creative Commons Attribution 4.0 International License. Read Full License 


\section{Abstract}

Background: This study aims to evaluate the effectiveness of Tumor Dissociation Enzyme (TDE) for the isolation of cryopreserved human ovarian cortex tissues, proposing an optimized applicable for artificial ovary.

Methods: This is a prospective experimental study. We present a comparative analysis among the outputs of follicles isolated from cryopreserved ovarian biopsies of ten young women undergoing laparoscopy. Follicles were isolated by Tumor Dissociation Enzyme (TDE) or Liberase Dispase High (DH) enzymatic digestion. Follicles were assessed by evaluating the number, viability, morphology, oxidative stress. Moreover, the follicle growth and viability were analyzed after eight days of in vitro culture (IVC) between each protocol.

Results: The recovery rate of follicles in Group 1 was significantly higher by 78 follicles compare to Group $2(p<0.05)$, while the difference in weight and volume of biopsies in both groups was no significant ( $p>$ $0.05)$. Group 1 allowed to isolate more primordial follicles $(p<0.05)$ and smaller diameter of follicles $(p<$ $0.01)$ than Group 2. Group 1 allowed to isolate $7 \%$ more of bright red follicles than Group $2(p<0.01)$. We also found that Group 1 had isolated a significantly higher percent of viable follicles $(p<0.05)$, more morphologically normal follicles $(p<0.05)$, and lower oxidative stress levels compared with Group $2(p<$ 0.01). The velocity of follicles growth from Day 0 to Day 8 in Group 1 was significantly higher $(p<0.05)$ than in Group 2. The viability of follicles on Day 8 of in vitro culture in Group 1 was significantly higher than Group $2(p<0.05)$.

Conclusions: TDE treatment can be an alternative for Liberase $\mathrm{DH}$, allows the isolation of highly viable follicles from the cryopreserved human ovarian cortex, with an intact morphology and low oxidative stress, and with high proliferation potential after culture in vitro.

\section{Background}

Current cancer therapy improvements have remarkably raised cancer patients' survival rates and prolong patients' life expectancy. However, Anti-cancer treatments such as chemo/radiotherapy often lead to irreversible side effects to cancer survivors: premature ovarian failure and infertility [1]. Cryo-banking ovarian tissue precedes anti-cancer therapy supplies hope in terms of future fertility reestablishment for patients who have no sufficient time to stimulate the ovary and cryopreserve embryo or oocyte [2]. However, reimplantation of cryopreserved ovarian tissue may reintroduce malignant cells and puts them at risk of disease recurrence $[3,4]$. However, it is known that the follicles surrounded by a layer of basement membrane can bar the blood capillaries, white blood cells and nerve processes, as a physiological barrier protecting follicles from contaminated by malignant cells of ovarian tissue [5]. Thus, embedded isolated preantral follicles in a bioengineered transplantable artificial ovary can be a safe, alternative treatment and may be regarded as an extension of cancer care. In this case we have decided 
to establish a standard protocol for the follicle isolation and choose a scaffold to support these follicles growth.

Numerous mechanical and enzymatic methods and their combination have been developed to isolate ovarian preantral follicles [6-8]. The mechanical method combined with different types of collagenase (Ia, II, IX, XI) alone or together with bovine pancreatic deoxyribonuclease I (DNase I) [8, 9], which avoids sticky DNA ends, may isolate more follicles in comparison with mechanical methods, However, it may damage the basement membranes and affect the viability of follicles [10]. Liberase, a mixture of purified enzymes, has been reported as a powerful tool to improve the isolated follicles' quality compared with collagenase [11]. Liberase DH (Dispase High) research grade belongs to the group of Liberase Research Grade with highly purified Collagenase I and Collagenase II blended together in a precise ratio and contains a high concentration of Dispase ${ }^{\circledR}$, a non-clostridial neutral protease (Sigma-aldrich $\mathrm{GmbH}$, Darmstadt, Germany). Moreover, others have shown that follicles isolated by Liberase DH had better morphology and high developmental competence compared with collagenase [12].

During enzyme isolation, increased proteolytic activity, cell lysis, and the liberate of DNA can hamper the isolated cells $[13,14]$. The release of DNA from dead cells induced the isolated cells cluster leading it challenging to digest the tissue and may also more comfortable to contaminate malignant cells in cancer patients. Besides DNase I can hydrolyze extracellular DNA released by degenerating cells without damaging intact cells, ensure the digestion not sticky and fit to handle [15]. Telfer et al. first introduced collagenase and DNase I to isolated many well-preserved preantral ovarian follicles of mice [16]. Xu et al. [17] retested using collagenase and DNase I to digest ovarian tissue of mice and culture isolated follicles in alginate bead and demonstrate average growth and development of follicles and oocytes. Wang et al. [18] using Liberase DH enzymatic solution containing DNase I to digest human cryopreserved ovarian tissue and get many good quality follicles.

Our prior study documented using "Tumor Dissociation Enzyme Reagent" (TDE, Innovative Diagnostic Systems Dr. Christian Sartori, Hamburg, Germany) to digested the cryopreserved ovarian tissue could yielded better viability follicles in contrast to Liberase TM [19]. Tumor Dissociation Enzyme (TDE) is a commercial enzyme-cocktail from the DCS ATP-Chemo-sensitivity Assay Kit (DCS Innovative DiagnostikSysteme, Hamburg, Germany) for gentle enzymatic digestion [20,21]. Prior studies in our group reported that TDE contains the mixture of highly purified collagenase and other enzymes that enable the digested suspensions to be not sticky, easy to isolate, and yield a higher number of healthy cells $[19,22]$. However, we do not know what effect this enzyme will have on follicular growth and development after in vitro culture.

We hypothesized that using of Tumor Dissociation Enzyme (TDE) may isolate many human follicles with proper morphology, vitality, and development potential after in vitro culture. To test this, we apply TDE to digest our cryopreserved ovarian cortex in comparison with Liberase DH combine with DNase I on the quantity and quality of isolated follicles and culture in alginate gel for eight days to analyze follicular growth of both enzymes. 


\section{Result}

\section{Number of retrieved follicles}

After enzymatic digesting of the frozen ovarian cortex 1502 follicles in both treatment groups were recovered. The most of follicles in both groups were almost fully isolated from the stromal tissue (Fig. 1A).

In treatment Group 1790 follicles using TDE enzyme cocktail were recovered and in treatment Group 2 712 follicles using Liberase DH/DNase enzyme cocktail were recovered (Table 1). As shown on Fig. 3A the recovery rate of follicles in Group 1 was significantly higher by 78 follicles compare to Group 2 ( $p<$ $0.05)$, while the difference on weight and volume of biopsies in both groups was no significant $(p>0.05$, Table 1).

Table 1

Follicles isolated from 10 frozen experiment ovarian tissues with different kinds of enzymes

\begin{tabular}{|c|c|c|c|c|c|c|c|}
\hline \multirow{3}{*}{$\begin{array}{l}\text { Number } \\
\text { of } \\
\text { patient }\end{array}$} & \multirow[t]{3}{*}{$\begin{array}{l}\text { Age } \\
\text { (years) }\end{array}$} & \multicolumn{2}{|c|}{$\begin{array}{l}\text { Enzymatic digestion } \\
\text { (follicles number) }\end{array}$} & \multicolumn{2}{|c|}{ Biopsy weight (g) } & \multicolumn{2}{|c|}{ Biopsy volume $\left(\mathrm{mm}^{3}\right)$} \\
\hline & & Group 1** & Group 2*** & $\begin{array}{l}\text { Biopsy } \\
\text { for }\end{array}$ & $\begin{array}{l}\text { Biopsy } \\
\text { for }\end{array}$ & $\begin{array}{l}\text { Biopsy } \\
\text { for }\end{array}$ & $\begin{array}{l}\text { Biopsy } \\
\text { for }\end{array}$ \\
\hline & & & & Group 1 & Group 2 & Group 1 & Group 2 \\
\hline 1 & 18 & 20 & 16 & 0.0186 & 0.0182 & 19 & 18 \\
\hline 2 & 22 & 201 & 186 & 0.2113 & 0.1907 & 150 & 147 \\
\hline 3 & 35 & 173 & 167 & 0.1932 & 0.2014 & 147 & 150 \\
\hline 4 & 21 & 152 & 143 & 0.2973 & 0.2759 & 185 & 179 \\
\hline 5 & 22 & 35 & 33 & 0.0953 & 0.113 & 52 & 54 \\
\hline 6 & 23 & 52 & 49 & 0.1519 & 0.1601 & 60 & 63 \\
\hline 7 & 19 & 21 & 17 & 0.0196 & 0.0189 & 20 & 19 \\
\hline 8 & 23 & 24 & 21 & 0.0352 & 0.0334 & 33 & 30 \\
\hline 9 & 22 & 17 & 14 & 0.0194 & 0.0187 & 20 & 19 \\
\hline 10 & 25 & 95 & 66 & 0.1231 & 0.126 & 57 & 60 \\
\hline Total & - & 790 & 712 & 1.1649 & 1.1563 & 743 & 739 \\
\hline $\begin{array}{l}\text { Mean } \pm \\
\text { SD }\end{array}$ & $\begin{array}{l}23 \pm \\
4.66\end{array}$ & $\begin{array}{l}79.00 \pm \\
71.246^{\star}\end{array}$ & $\begin{array}{l}71.20 \pm \\
67.715\end{array}$ & $\begin{array}{l}0.116 \pm \\
0.09\end{array}$ & $\begin{array}{l}0.115 \pm \\
0.09\end{array}$ & $\begin{array}{l}74.30 \pm \\
62.30\end{array}$ & $\begin{array}{l}73.90 \pm \\
61.44\end{array}$ \\
\hline
\end{tabular}

* The number of retrieved follicles independently from their maturity was significantly higher in group 1 in comparison with group $2(p<0.01)$. 
** Group 1 - TDE: (Dr. Christian Sartori, Labour, Hamburg, Germany) is a commercial Enzyme - cocktail (Patent Nr. WO 2006031867 A2, 2004).

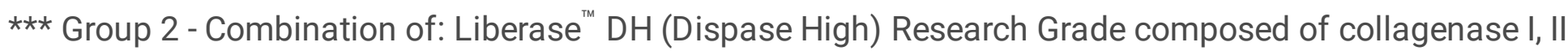
and the neutral protease Dispase ${ }^{\circledR}$ (Sigma-Aldrich Chemie, GmbH, Schnelldorf, Germany) and DNase I (Bovine pancreatic deoxyribonuclease I) which is a DNA minor grove-interacting nuclease with relatively low specificity (Sigma-Aldrich Chemie, GmbH, Schnelldorf, Germany).

On Fig. 3A has been presented the data of follicles recovery with different maturity. From these follicles distribution possible to see that the enzyme cocktail of treatment Group 1 (TDE) allowed to isolate more primordial follicles than enzyme cocktail of Group 2 (Liberase DH/DNase) as follow: $80.5 \pm 5.4 \%$ vs 77.7 $\pm 5.2 \%$, respectively $(p<0.05)$.

The percentage of recovered primary and secondary follicles was no significant different between Group 1 and Group 2 (primary follicles: $17.8 \pm 5.6 \%$ vs $20.7 \pm 4.8 \%$; secondary follicles: $1.6 \pm 1.3 \%$ vs $1.6 \pm 1.6 \%$, respectively, $p>0.05)$.

The comparison of follicles diameter in both treatment groups (Fig. 3B) has shown that follicles of Group 1 has significantly smaller diameter than the follicles of Group 2: $44.5 \pm 11.4 \mu \mathrm{m}$ vs $45.8 \pm 11.1 \mu \mathrm{m}$, respectively, $p<0.01$.

\section{Viability assessment of retrieved follicles}

\section{Neutral red dye}

A total of 1502 follicles were stained with neutral red dye. The viability of follicles using express staining with neutral red dye have presented on Figure 4A. The data have shown that TDE-cocktail enzyme of Group 1 allowed to isolate $7 \%$ more $(p<0.01)$ of bright red follicles than Liberase DH/DNase enzyme cocktail of Group $2(70.9 \pm 4.7 \%$ vs $63.9 \pm 4.2 \%$, respectively). It was also noted that percent of follicles stained in light red colour in treatment group Group 2 was 5\% more $(p<0.01)$ than in Group $1(17.9 \pm$ $4.8 \%$ vs $23,0 \pm 3.7 \%$, respectively). However, the percent of non-stained follicles was not significantly different $(p>0.05)$ in both treatment groups $(12.3 \pm 5.5 \%$ of Group 1 vs $13.1 \pm 3.3 \%$ of Group 2 , respectively).

\section{Calcein AM and ethidium homodimer-1}

A total of 317 follicle were stained with Calcein AM in combination with ethidium homodimer- 1 . The viability of follicles with commonly used fluorescence dye Calcein AM in combination with ethidium homodimer-1 presented on Figure 4B.

The data have shown that the percent of follicles of class V1 in Group 1 was for 9.6 significantly higher $(p<0.05)$ than in Group $2(64.8 \pm 5.2 \%$ vs $55.2 \pm 6.2 \%$, respectively $)$. 
The percent of class V3 follicles in Group 2 was significantly higher $(p<0.05)$ than in Group $1(14.5 \pm$ $5.9 \%$ vs $9.7 \pm 4.7 \%$, respectively). However, the percent of class V2 and V4 follicles was not significantly different $(p>0.05)$ in both treatment groups.

\section{ROS assay}

To measure the amount of ROS in live cells a total of 20 isolated follicles in each treatment group were stained with CellROX ${ }^{\circledR}$. The data presented on Figure $4 \mathrm{C}$ have shown that generally the oxidative stress was very low in both treatment groups, but nevertheless the percent of oxidative level was significantly lower $(p<0.01)$ in Group 1 than in Group $2(0.2 \pm 0.2 \%$ vs $2.1 \pm 1.9 \%$, respectively).

\section{Morphology assessment}

The evaluation of follicles' morphology using fluorescence dyes anti-a-Tubulin antibody in combination with DAPI presented on Figure 5.

In this experiment a total of 317 follicles were assessed. It was found that percent of morphologically normal follicles of class M1 was significantly higher $(p<0.05)$ in Group 1 compared to Group $2(72 \pm$ $4.2 \%$ vs $65.7 \pm 5.1 \%$, respectively). However, the morphology of follicles of class M2, M3 and M4 was not significantly different $(p>0.05)$ between these treatment groups (Group 1 compared to Group 2 as: class M2: $16.7 \pm 4.6 \%$ vs $17.9 \pm 4.5 \%$; class M3: $8.2 \pm 4.6 \%$ vs $8.8 \pm 4.5 \%$; class M4: $3.1 \pm 4.1 \%$ vs $7.7 \pm 4.7 \%$, respectively).

\section{In vitro culture of follicles in 3D system using alginate scaffold}

For embedding in alginate beads (Fig. 6A) and in vitro culture a total of 53 isolated follicles in each treatment group were used.

The in vitro culture of embedded follicles during 8 days is presented on Figure 6B, C. It is shown that the diameter of the follicles on day 0 in both treatment groups (Group 1: $40.5 \pm 4.1 \mu \mathrm{m}$; Group 2: $42 \pm 3.5 \mu \mathrm{m}$ ) was not significantly different $(p>0.05)$. The measurement of size of follicles after 8 days in vitro culture has shown that of diameter of follicles was non-significantly increased $(p>0.05)$ in both treatment groups (Group 1: $69.6 \pm 8.4 \mu \mathrm{m}$ vs Group 2: $64.3 \pm 7.2 \mu \mathrm{m}$ ).

However, we have noted that the velocity of follicles growth (Fig. 6D) from Day 0 to Day 8 in Group 1 was significantly higher $(p<0.05)$ than in Group $2(29.1 \pm 9.2 \%$ vs $22.3 \pm 8.6 \%$, respectively). The data of viability of follicles on Day 8 after staining with Calcein AM and ethidium homodimer- 1 for identifying of live and dead cells presented on Figure $6 \mathrm{E}$. The data shown that the percent of follicles of class V1 + V2, which represented of viable follicles, was significantly higher $(p<0.05)$ in treatment Group 1 compare to Group 2 (68.9 $\pm 5.8 \%$ vs $49.5 \pm 9.4 \%$, respectively).

\section{Discussion And Conclusion}


Our results indicate that a new enzymatic digestion protocol using TDE, a commercial enzyme-cocktail, is initiated for human follicle isolation as the first step to bioengineer a transplantable artificial ovary. The efficiency, safety and productivity of the proposed protocol can be a suitable method for isolating plenty of intact and viable follicles with good growth potential. Our goal is to replace Liberase DH as enzyme digestion on the first step in constructing artificial ovaries for female cancer patients preventing disease recurrence and clinical application.

The ovarian tissue freezing and thawing protocol in our previous studies have shown promising results in viability and developmental and have a live birth after auto-seeding of cryopreserved ovarian tissue [22, 23]. Therefore, we are confident to use cryopreserved tissue. To assess enzyme TDE, we compared it with Liberase DH combined with DNase I which is widely used as the gold standard for human follicle digestion $[18,24,25]$.

\section{Yield of isolated follicles}

In our study, considering the similar size of the digested ovarian cortex, the recovery rate of follicles in Group 1 was significantly higher by 78 follicles compare to Group $2(p<0.05$, Table 1$)$, especially on primordial follicles $(80.5 \pm 5.4 \%$ vs $77.7 \pm 5.2 \%, p<0.05)$. Weight and volume of biopsies in both group was no significant $(p>0.05)$. This was similar to a recent study by Schmidt et al. It showed that the number of follicles isolated by TDE digestion is also significantly higher than using Liberase TM [19]. By comparison, Lierman et al. presented that no statistical differences were found between Liberase TM and Liberase $\mathrm{DH}$, concerning the number and type of isolated follicles [26]. Follicles diameter in Group 1 has significantly smaller than Group $2(44.5 \pm 11.4 \mu \mathrm{m}$ vs $45.8 \pm 11.1 \mu \mathrm{m}, \mathrm{p}<0.01)$. This were similar to the result obtained by Mouloungui et al. who reported the similar mean diameter of follicles treatment by Liberase DH $(45.2 \pm 8.2 \mu \mathrm{m})[27]$.

As the ovarian cortex holds a vastly dense and fibrous structure, it is crucial using a suitable enzymatic digestion protocol to maximize the yield of isolated follicles from the neighboring tissue. Liberase $\mathrm{DH}$ Research Grade contains highly purified Collagenase I and Collagenase II blended in a precise ratio to each other and contains a high concentration of Dispase ${ }^{\circledR}$ (www.Sigma-Aldrich.de). Compared to widely use of Liberase $\mathrm{DH}$, we can assume that TDE not only contains highly purified collagenase, and may also include other enzymes: protease, dispase, or DNase can fully digested human ovarian tissues.

\section{Quality of isolated follicles}

Quality analysis of the isolated follicles in our project was based on follicle viability assessment by neutral red dyes, vital fluorescent dyes, ROS assay, and on the general follicle morphology assessment using fluorescence dyes.

Follicle viability assessment with neutral red dye The advantages of neutral red dye are that the dye can be reconstituted in physiological medium, is non-toxic and can be easy to visualized under a standard light microscopy, it is proved to be no long-term deleterious effects on the follicles [28]. Neutral Red (NR) 
is a vital dye that readily diffuses through the cell membrane and concentrates in lysosomes of viable cells [29] shows a deep red colour (Fig. 1A). It is thus easy to distinguish between viable, damaged or dead cells [30]. Our study presented the percentage of bright red follicle in Group 1 digested from cryopreserved ovarian tissue was found to be significantly higher $(p<0.01)$ than Group $2(70.9 \pm 4.7 \%$ vs $63.9 \pm 4.2 \%$, respectively), similar to the observations of intense red -stained follicles in the suspension of cryopreserved ovarian tissues made by Schmidt et al. (70.3 $\pm 6.2 \%$ in TDE vs $53.1 \pm 2.0 \%$ in Liberase TM, respectively) [19].

Since mechanical isolation of follicles without using enzyme can have less negative effect on the isolated follicles, we first tested different mechanical methods introduced by previous studies. However, in our unpublished result we found that using a tissue chopper (Mcllwain Tissue Chopper, The Mickle Laboratory, Guildford, UK) can get more preantral follicles while less viable follicles with little percentage of intense red-stained follicles than scalpels. The use of tissue chopper could dramatically damage follicles, these damages were affected by the interval of serial sections; The smaller of the interval of serial section, the more damaged follicles we get (our unpublished result). It was comparable with Lucci et al. who presented that the smaller use of cut intervals by tissue chopper, the more destroyed preantral follicles, while the largest intervals may reduce the efficiency of mechanical dissociation of the ovarian fragments [31]. In contrast to our finding, mechanical isolation technique using a tissue chopper could isolate large numbers of morphologically normal preantral porcine follicles than scalpels no matter changing incubation time or size of the tissue pieces [32].

Viability assessment using Calcein AM and ethidium homodimer-1 While follicles stained with Calcein AM in combination with ethidium homodimer-1, our data have presented that Group 1 had isolated more viable follicles than Group 2 (class V1: $64.8 \pm 5.2 \%$ vs $55.2 \pm 6.2 \%$, respectively). Liberase DH Research Grade contains highly purified Collagenase I and Collagenase II, endotoxin is one of the detrimental components of collagenase extract, maybe reduce the vitality of follicles [33]. Indeed, for Liberase $\mathrm{DH} / \mathrm{DNase}$ treatment, the percentage of class $\mathrm{V} 1$ follicles in our study was in accordance with previous reports: 65\% (digested from cryopreserved ovarian cortex) [26] and 61\% (digested from fresh ovarian cortex) [11]. Other observations shown by Dolmans et al. [11], observed other observations that early atresia were frequently found in follicles isolated by Liberase. This may infer that Liberase may alter the viability of isolated follicles by inducing apoptosis [34].

Viability assessment by ROS assay Reactive oxygen species make a vital part as mediators of various intracellular signaling pathways [35] regulating apoptosis and necrosis [36]. Oxidative stress is the result of an imbalance in the production and elimination of the intracellular reactive oxygen species (ROS). However, a high level of oxidative can damaging follicle [37] and affecting their in vitro culture [38]. A high concentration of oxidative may also gap mitochondrial membrane pores, emit cytochrome and trigger caspases, with following apoptosis [39] and affect oocyte maturation [40]. In our result, the percent of oxidative level was significantly lower $(p<0.01)$ in Group 1 than in Group $2(0.2 \pm 0.2 \%$ vs $2.1 \pm 1.9 \%$, respectively). Collectively, our results suggest that reactive oxygen species generation were triggered during Liberase isolation procedures. Tirmenstein et al. found that Liberase, contains highly purified 
Collagenase can induces oxidative stress after isolation of hepatocytes, leading to a loss of cytochrome enzyme activity [41]. Liberase, which contains very low levels of endotoxin, still produced nitrite. Nitric oxide (NO) which is produced by nitric oxide synthase (NOS) can react with superoxide anion to form the reactive oxidant species [42]. Similar observations were made by Forstermann et al. [43] that endotoxin has been shown to induce NOS in cells leading to the increase of ROS. Therefore, we can deduce that TDE may well preserve ROS balance and reduce oxidative stress.

Morphology Our result presented that on the percent of morphologically normal follicles of class M1 was significantly higher $(p<0.05)$ in Group 1 compared to Group $2(72 \pm 4.2 \%$ vs $65.7 \pm 5.1 \%$, respectively). It was indicated that using TDE digestion can well preserve the morphology and granulosa cell layer of follicle. Laminin and collagen IV which are essential components of the basement membrane of human primordial follicles [44]. Liberase DH presents a high concentration of dispase, although it does not cleave laminin, but it can cleave fibronectin and collagen IV [45], and damage the junction and membrane of the follicle, that would probably explain our result of damaged follicles or extruded oocytes in Liberase $\mathrm{DH} / \mathrm{DNase}$ group. This is in accordance with previous investigations were made by Dolmans et al. [11] and Oktay et al. [46] suggest that enzymatic isolation using Liberase may induce slight morphofunctional changes in the follicular cell compartment, such as alteration in shape or extensive disruption to the follicular wall.

\section{Culture of isolated follicles}

Culture of isolated preantral follicles has several potential applications, including in vitro culture and grafting or bioengineering a transplantable artificial ovary or for molecular biology analyses. Therefore, ecsuring good viability, preserving well structure and maintaining follicular development is essential before attempting such approaches in humans. Observations in preliminary studies reported that follicles isolation using Liberase were degenerated in vitro culture [8]. Thus, to examine the effect of different types of enzymic digestion on the follicle, we isolated follicles from cryopreserved ovarian cortex embedded in 3D alginate scaffold for in vitro culture 8 days.

After 8 days of in vitro culture in our study, follicles isolated from both TDE and Liberase DH/DNase treatments can maintain good viability and preserved well 3D structure, and an increase in size in both groups. Our results are similar to those follicles obtained by Yin et al. [47] with 7 days in vitro culture. Such an increase in follicle diameter after IVC may be due to some products generated during ovarian tissue cryopreservation: hypoxia, increasing of intracellular $\mathrm{Ca}^{2+}$, osmotic disruption of cellular membranes, generation of reactive oxygen species (ROS) and lipid peroxidation. These products generate by cryopreserved or ovarian cortex chopped by a tissue sectioner and follicles isolated by enzyme may interrupt ovarian Hippo signaling and activate follicle in vitro culture [48]. Besides, our result noted a greater growth on the velocity of follicles from Day 0 to Day 8 in Group 1 was significantly higher $(p<$ $0.05)$ than in Group $2(29.1 \pm 9.2 \%$ vs $22.3 \pm 8.6 \%$, respectively). The data of viability of follicles on Day 8 shown that the percent viable follicles, was significantly higher $(p<0.05)$ in treatment Group 1 compare to Group $2(68.9 \pm 5.8 \%$ vs $49.5 \pm 9.4 \%$, respectively). Liberase, which contains very low levels of 
endotoxin, still produced nitrite [42], can induce oxidative stress in follicle after enzymatic isolation [41], induce apoptosis in vitro culture [33], strongly delay and impair grafting outcomes [34]. These probably reflecting Liberase may weaken the initial health status of isolated follicles or a lack of factors essential to sustaining their survival and growth [49]. Based on these results presented after IVC, we can assume that TDE can well preserve follicles during digestion better than Liberase without impairing their ability to survive and grow in vitro.

To our knowledge, this study was the first to provides insight into the relationships between morphology, viability, cell intact, oxidative stress and diameter of growing preantral follicles between TDE and Liberase DH digestion. Gap junction formation based on the ability of the oocyte to communicate with granulosa cells and signal for cell division between oocytes and granulosa cells may explain the differences in growth rate in both groups. Our finding supports the hypothesis that using TDE digestion can well preserve granulosa cell-oocyte contact which is important for cell proliferation in early stages. Our study had several limitations: First it did not evaluate the potential of isolated follicles contamination by cancer cell; Second, it did not examine the RNA expression levels of each oocyte and granulosa cell from a single follicle. Additional studies are needed to confirm the isolated follicle with the risk of cancer cell reseeding by enzymatic digestion and isolated human ovarian follicles' RNA levels.

\section{Conclusion}

In conclusion, this study using tumor dissociation enzyme (TDE) to isolated follicles can allow us to obtain a high number of viable follicles from the human ovarian cortex in contrast with the earlier described Liberase DH method, which is the initial and crucial step to construct an artificial ovary for future clinical applications. With our isolation technique, will enable a foundation as research is increasingly focusing on preantral folliculogenesis.

\section{Materials And Methods}

All chemicals were purchased from Sigma (Sigma-Aldrich Chemie, GmbH, Schnelldorf, Germany) except where otherwise stated.

\section{Collection, dissection and distribution into treatment groups}

The presented study was approved by the Ethics Board of the Cologne University, Germany. Informed consent was given by 10 patients aged 18 to 35 years $(23.8 \pm 4.66)$ years. These patients were undergoing laparoscopic surgery within the FertiProtect program at the Department for Gynecology and Obstetrics of the University Hospital of Cologne.

All ovarian tissue used for this research were cryopreserved and stored at the cryo-bank of the Maternal Hospital of Cologne University. 
According to protocol approved in our department, $10 \%$ of ovarian tissue collected from patients was used for 'patient-oriented' to assess the tissues' viability for re-transplantation.

The collection and transport of ovarian tissue were performed as follow: immediately after surgical recovery the ovarian tissue was located in a sterile $100 \mathrm{ml}$ specimen container (Sarstedt, Nümbrecht, Germany) filled with $50 \mathrm{ml}$ of a basal medium composed from Leibovitz L-15 supplemented with $5 \%$ Dextran Serum Substitute (Irvine Scientific, Santa Ana, USA). A closed specimen container was transported within 3 minutes at room temperature to the laboratory. The dissection of the ovarian cortex from the medulla was done using sterile surgical tweezers and scalpels no. 22 at room temperature. A small part of the ovarian cortex piece (OCP, $\sim 1 \mathrm{~mm}^{3}$ ) was fixed in Bouin's solution for later evaluation of quality and density of follicles. Then the medulla part of ovarian tissue pieces was immediately removed using sterile surgical tweezers with scalpel no. 22 , and $10 \%$ of ovarian tissue was cut for patient-oriented research. The pieces were cooled to $5^{\circ} \mathrm{C}$ for $24 \mathrm{~h}$ in $50 \mathrm{ml}$ of Leibovitz L-15 with $5 \%$ Dextran Serum Substitute before the freezing procedure was performed. The size of OCPs for patient-oriented research in this study depended on the amount of surgically recovered ovarian tissue and ranged from 37 to 364 $\mathrm{mm}^{3}$ (Table 1). After this, the piece was frozen and stored in liquid nitrogen vapor until use.

\section{Ovarian tissue freezing and thawing}

The cryopreservation of OCPs was performed according to our protocol as previously published [23]. On freezing day, the OCPs were placed for $30 \mathrm{~min}$ at room temperature in a 20-ml freezing medium composed of basal medium supplemented with $6 \%$ dimethyl sulfoxide, $6 \%$ ethylene glycol, and $0.15-\mathrm{M}$ sucrose. After this, the OCPs were located into a standard 5-ml cryo-vials (Thermo Fisher Scientific, Rochester, NY, USA) previously filled with $4.5 \mathrm{ml}$ freezing medium and frozen using IceCube $14 \mathrm{~S}$ programmable freezer (Sy-Lab, Neupurkersdorf, Austria). The slow cooling profile started at $-6^{\circ} \mathrm{C}$, and the samples were then cooled from $-6{ }^{\circ} \mathrm{C}$ to $-34^{\circ} \mathrm{C}$ at a rate of $0.3^{\circ} \mathrm{C} / \mathrm{min}$. At $-34^{\circ} \mathrm{C}$, the cryo-vials were finally plunged into liquid nitrogen and stored until thawing. The freezing protocol for cryopreservation of ovarian tissue included an auto-seeding step at $-6^{\circ} \mathrm{C}$.

The thawing of frozen probes was performed as follow: the removed from liquid nitrogen cryo-vial was hold at room temperature in air for 30 seconds with subsequent, direct immersion in boiling water bath $\left(100^{\circ} \mathrm{C}\right)$ for 60 seconds. The exposure time in the boiling water was visually controlled by ice apex in the medium. As soon as the ice apex became 2 to $1 \mathrm{~mm}$ thick, the cryo-vial was removed from the boiling water. At this point, the final temperature of the medium was between $4^{\circ} \mathrm{C}$ and $10^{\circ} \mathrm{C}$. The thawed $\mathrm{OCPs}$ were immediately transferred from the cryo-vials to a $10 \mathrm{ml}$ thawing solution (basal medium containing 0.5-M sucrose) in a $100 \mathrm{ml}$ specimen container (Sarstedt, Nümbrecht, Germany). For dilution of cryoprotectants from thawed tissue, the stepwise rehydration technique was applied due to drop by drop addition of basal medium to the solution of sucrose with OCPs. This rehydration step was performed in combination with continuous shaking of specimen containers with OCPs with 200 OSC/min during 15 minutes at room temperature. During these rehydration time, the $50-\mathrm{ml}$ of a basal medium was dropped into the specimen container. The final concentration of sucrose was $0.083-\mathrm{M}$, resulting in almost isotonic 
conditions. After the rehydration time was over, the three wash steps in a fresh basal medium for 10 minutes was performed.

\section{Isolation and collection of follicles}

After warming, the OCPs were cut into two equal parts. Each part of OCPs was weighted using an analytical balance (Ohaus EP64C Explorer Pro Analytical Balance, Ohaus Corporation, USA) and the volume of the piece was measured (Table 1). A total of 10 OCPs in each treatment group were evaluated.

Our research compared two enzyme-cocktails' influence on viability and ability to in vitro growth in a 3dimensional system (3D) of preantral follicles recovered from the cryopreserved ovarian cortex.

The tested enzyme-cocktails were:

1. "Tumor Dissociation Enzyme Reagent" (TDE) from the DCS ATP-Chemo-sensitivity Assay Kit (DCS Innovative Diagnostik-Systeme, Dr. Christian Sartori Labor, Hamburg, Germany) which composed of various types of highly purified collagenase (personal communication with Dr. Christian Sartori Labor, Hamburg, Germany) and is a commercial enzyme-cocktail for enzymatic digestion of any solid tumors $[20,21,50]$.

2. Combination of: Liberase DH (Dispase High) Research Grade composed of collagenase I, II and the neutral protease Dispase ${ }^{\circledR}$ (Sigma-Aldrich Chemie, GmbH, Schnelldorf, Germany) and DNase I (Bovine pancreatic deoxyribonuclease I) which is a DNA minor grove-interacting nuclease with relatively low specificity (Sigma-Aldrich Chemie, GmbH, Schnelldorf, Germany) [18, 47].

For this research, 10 frozen OCPs immediately after warming were cut into two equal parts and randomly distributed in two treatment groups as follows: Group 1 - 10 OCPs for the enzymatic digestion with TDE enzyme-cocktail and Group 2 - 10 OCPs for the enzymatic digestion with Liberase DH/DNase enzymecocktail.

The procedure of follicle isolation was performed as described previously $[18,19]$ with some modification. Briefly, the OCPs were mechanically cut into $\sim 0.5 \times 1$ to $1 \times 1 \mathrm{~mm}^{3}$ pieces by quick simultaneous movements of two scalpels no. 22 on a sterile $100 \mathrm{~mm}$ Falcon Petri dish (Falcon, Corning Incorporated-Life Science, Corning, USA) under a stable temperature cooling on ice to $+4{ }^{\circ} \mathrm{C}$. Then the minced ovarian cortical tissue was suspended in basal medium containing $16 \%$ of TDE-enzymatic solution (Group 1) or in basal medium containing 0.28 Wünsch units $/ \mathrm{mL}$ Liberase $\mathrm{DH}$ in basal medium plus $10 \mu \mathrm{g} / \mathrm{ml}$ DNase I (Group 2). The $50 \mu \mathrm{g} / \mathrm{ml}$ of neutral red (NR) dye was added to digesting each treatment group's solutions for quick and roughly visualization of isolated follicles [29]. This vitality dye shows a deep red color in acid cell structures and is normally used for the express estimation of viable follicles (Fig. 1A). The incubation time for both treatment groups was 75 minutes at $37^{\circ} \mathrm{C}$ on $\mathrm{KS} 260$ basic shaker (IKA, Staufen, Germany) with 120 rotations/minute with additional every 15 minutes of 
gentle pipetting with a $1 \mathrm{ml}$ pipette. Enzymatic digestion was terminated by adding an equal volume of $4^{\circ} \mathrm{C}$ cold Leibovitz L-15 medium supplemented with $20 \%$ fetal calf serum.

The follicles were collected with $125 \mu \mathrm{m}$ V-denuded capillaries (Vitromed $\mathrm{GmbH}$, Jena, Germany) one by one (no more than $45 \mathrm{~min}$ ) by two experienced operators under a light inverted stereomicroscope Nikon SMZ1270 (Nikon, Düsseldorf, Germany) and washed three times in $4{ }^{\circ} \mathrm{C}$ basal medium. The follicle diameter was measured by the basement membrane surrounding the granulosa cell layer(s) as the follicular boundary under Program Zen (Nikon, Düsseldorf, Germany), two perpendicular measurements were made at right angles to each other and the mean diameter was calculated. The preantral stages of follicles were classified according to Gougeon and Fortune [51, 52] as follow: primordial follicle $(<60 \mu \mathrm{m})$, oocytes surrounded by a single layer of flattened pre-granulosa cells; primary follicle ( $>60 \mu \mathrm{m}$ to $\leq 75$ $\mu \mathrm{m})$, oocytes with a single layer of cuboidal granulosa cells; secondary follicle ( $>75 \mu \mathrm{m}$ to $<200 \mu \mathrm{m})$, with at least two complete layers of granulosa cells.

\section{Follicle viability assessment with fluorescence dye Calcein AM and ethidium homodimer-1}

The stained isolated with neutral red follicles were subjected to fluorescent staining with Calcein AM and ethidium homodimer-1 [53]: Briefly: the follicles were exposed to $2 \mu \mathrm{M}$ of Calcein AM and $5 \mu \mathrm{M}$ of ethidium homodimer-1 in Dulbecco's phosphate buffer saline (DPBS) and incubated for $45 \mathrm{~min}$ at $37^{\circ} \mathrm{C}$ in the dark. Non-fluorescent cell-permeant Calcein AM enters the cell and cleaved by esterase in living cell giving an intense green fluorescence (excitation/emission, $495 \mathrm{~nm} / 515 \mathrm{~nm}$ ). Ethidium homodimer-1 enters cells with damaged membranes binding to nucleic acids of dead cells and shows a red fluorescence (excitation/emission, $528 \mathrm{~nm} / 617 \mathrm{~nm}$ ). After exposure to fluorescence dyes, follicles were washed in DPBS and observed under a confocal microscope (Olympus Fluoview FV 1000, Hamburg, Germany). The viability of follicles was classified into four categories depending on the percentage of dead granulosa cells [11]: V1, live follicles with the oocytes and all granulose cells (GCs) viable; V2, minimally damaged follicles with $<10 \%$ of dead GCs; V3, moderately damaged follicles with $10-50 \%$ dead GCs; V4, dead follicles with both the oocyte and/or > 50\% GCs dead (Fig. 1B - E).

\section{Viability assessment due to measurement of Oxidative stress level of isolated follicles}

The isolated follicles were staining with CellROX ${ }^{\circledR}$ Deep Red fluorogenic probe (Life Technologies, New York, USA), which was designed to reliably measure reactive oxygen species (ROS) in live cells. This dye applies specially to detect cellular superoxide anion $(\mathrm{O} \cdot \cdot-)$ and hydroxyl radical $(\mathrm{OH} \cdot)$ and produces deep red fluorescence (excitation/emission, $640 \mathrm{~nm} / 665 \mathrm{~nm}$ ). The staining procedure was performed according to Korkmaz [54]. Briefly: the follicles were fixed in formalin, washed twice with DPBS, incubated in CellROX ${ }^{\circledR}$ Deep Red Reagent and anti-a-Tubulin antibody for 30 minutes at $37^{\circ} \mathrm{C}$ in the dark. After incubation, follicles were cover by Fluoromount-G mounting medium containing 4',6-diamidino-2phenylindole (DAPI, Fluoromount-G ${ }^{\text {T' }}$ with DAPI; Thermo Fisher Scientific), and then observed under a confocal microscope (Olympus Fluoview FV 1000, Hamburg, Germany). To measure the level of oxidative stress, follicles stained by DAPI show the deep blue fluorescence of cells' DNA. The incubation of follicles 
with the anti-a-tubulin antibody produces a green fluorescence. The incubation of follicles with CellROX ${ }^{\circledR}$ Deep Red Reagent shows a deep red fluorescence of reactive oxygen species in cells (Fig. 1F). Semiquantification of the oxidative level was calculated by using Fiji software (version 1.40; National Institute of Health, Bethesda, MD) and the percentage of oxidative level (\%) was calculated in these two digestion groups.

\section{Follicle morphology assessment with fluorescence dye}

The morphological evaluation of follicles were performed according to their morphology and integrity of granulosa cell layer [11] by staining with the anti-a-Tubulin antibody in combination with DAPI. To contrast the cytoskeletal a-tubulin the specific to the anti-a-tubulin antibody producing green fluorescence (excitation/emission, $500 \mathrm{~nm} / 520 \mathrm{~nm}$ ) was applied. To contrast the nuclei of follicular cells the DAPI was applied. This dye binds to DNA and RNA of nuclei of follicular cells, producing blue fluorescence (excitation/emission, $360 \mathrm{~nm} / 460 \mathrm{~nm}$ ). The fluorescent-stain procedure was performed as follow: isolated follicles were fixed in formalin, washed twice with DPBS, and then stained with anti-a-Tubulin antibody for 30 minutes at $37^{\circ} \mathrm{C}$ in the dark. After incubation, follicles were cover by Fluoromount-G mounting medium containing DAPI and observed under a confocal microscope (Olympus Fluoview FV 1000, Hamburg, Germany). According to performed staining the follicles were classified into four categories as follow: M1, spherical form with complete granulosa cell layer; M2, irregular form with complete granulosa cell layer; $\mathrm{M} 3$, irregular form with $<10 \%$ granulosa cell loss; and M4, totally atypical form with $10-50 \%$ granulosa cell loss (Fig. 2).

\section{Follicle embedding and in vitro culture}

Immediately after isolation, only well morphologically preserved follicles stained bright red were collected for embedding in alginate scaffold and in vitro culture (Fig. 1A, white asterisk).

For embedding of isolated follicles in a sodium alginate scaffold, we have performed the technique previously described by the research group of Donnez [55] with some modification. Shortly: the isolated neutral red stained follicles were randomly distributed in two groups and transferred into $1.5 \%(\mathrm{w} / \mathrm{v})$ sodium alginate solution. Then the follicles using $20 \mu \mathrm{l}$ Eppendorf pipette were gently released into a plastic Petri dish containing $0.1 \mathrm{M} \mathrm{CaCl}_{2}$ solution for 2 minutes to cross-link. To wash out the $\mathrm{CaCl}_{2}$ solution each alginate scaffold contained $5-10$ follicles/bead was three times washed in serum-free culture medium (AIM V medium; Thermo Fisher Scientific) supplemented with $100 \mathrm{lU} / \mathrm{ml}$ penicillin, 100 $\mathrm{mg} / \mathrm{ml}$ streptomycin, $5 \%$ dextran sulfate sodium (DSS), $1 \%$ insulin-transferrin-selenium (ITS), $50 \mu \mathrm{g} / \mathrm{ml}$ ascorbic acid, $2 \mathrm{mM}$ Glutamax-1, $50 \mathrm{mIU} / \mathrm{ml} \mathrm{FSH}$ ). After washing, each alginate scaffold transferred into $500 \mu \mathrm{l}$ of culture medium/well of 24-well plate (Cell culture plate, Sigma - Aldrich, USA). The culture was performed at $37.5^{\circ} \mathrm{C}$ under $5 \% \mathrm{CO}_{2}$ for up to 8 days (Fig. $6 \mathrm{~A}$ ). Every second day the half of the culture medium with a fresh one was replaced. Every 2 day the follicles were observed and photographed under a standard light microscope. The follicles' diameter was calculated by averaging two perpendicular 
measurements from the basement membrane surrounding the granulosa cell layers as the follicular boundary under Program Zen (Nikon, Düsseldorf, Germany).

After 8 days of in vitro culture, all scaffolds with follicles were washed with PBS, then lysed using the alginate lyase buffer (Alginate Lyase, Sigma - Aldrich, Chemie, GmbH, Schnelldorf, Germany). For viability evaluation, all recovered from the sodium alginate scaffold follicles were incubated with Calcein AM and ethidium homodimer-1.

\section{Statistical analysis}

For statistical analysis, the confocal images were processed and analyzed using program Fiji, Statistical Product and Service Solutions (SPSS) 19.0 softwareand (Chicago, IL, USA). The Kruskal - Wallis tests statistically analyzed data. P-Values less than 0.05 as statistically significant was considered, and the results as the mean standard error were expressed. All experiments in triplicate were performed.

\section{Abbreviations}

TDE: Tumor dissociation enzyme; Liberase DH: Liberase Dispase High; Liberase TM: Liberase Thermolysin Medium; DNase: Deoxyribonuclease; 3D: 3-dimensional system; IVC: In vitro culture; NR: Neutral red; DNA: Deoxyribonucleic acid; RNA: Ribonucleic acid; OCP: ovarian cortex piece; PBS:

Phosphate buffered saline; DPBS: Dulbecco phosphate buffer saline; GCs: Granulose cells; ROS: Reactive oxygen species; O\--: Superoxide anion; $\mathrm{OH} \bullet$ : Hydroxyl radical; DAPI: 4',6-diamidino-2-phenylindole; DSS: Dextran Sulfate Sodium; ITS: insulin-transferrin-selenium; FSH: Follicle stimulating hormone; NO: Nitric oxide; NOS: Nitric oxide synthase; SPSS: Statistical Product and Service Solutions; SEM: Standard error of mean.

\section{Declarations}

\section{Acknowledgements}

The authors thank all personnel involved in the clinical activities in fertility preservation for their passionate work. The women donating their ovarian tissue for research are also greatly appreciated.

\section{Authors' contributions}

Conceived and designed the experiments: $\mathrm{El}, \mathrm{JC}, \mathrm{VI}$, and GR. Performed the experiments and carried out data analysis: El, JC. Original draft writing: JC, XD, WW; Manuscript drafting and critical discussion: El, VI, JC, MW, PM and PT. All authors read and approved the final manuscript.

\section{Funding}

The authors did not receive any specific funding for this study. 
Availability of data and materials

The dataset used in current study is available from the corresponding author on reasonable request.

\section{Ethics approval and consent to participate}

This study was approved by the Ethics Boards of University Cologne (applications 9 99,184 and 13 147). Written informed consent was obtained from all the participating couples.

\section{Consent for publication}

All authors agree to the submission of this article for publication.

\section{Competing interests}

The authors declare that they have no competing interests.

\section{References}

1. Wenners A, Grambach J, Koss J, Maass N, Jonat W, Schmutzler A, et al. Reduced ovarian reserve in young early breast cancer patients: preliminary data from a prospective cohort trial. BMC Cancer. 2017; 17(1): 632.

2. Turan V, Oktay K. Sexual and fertility adverse effects associated with chemotherapy treatment in women. Expert Opin Drug Saf. 2014;13(6):775-83.

3. Rosendahl M, Andersen MT, Ralfkiær E, Kjeldsen L, Andersen MK, Andersen CY. Evidence of residual disease in cryopreserved ovarian cortex from female patients with leukemia. Fertil Steril. 2010;94(6):2186-90.

4. Dolmans MM, Marinescu C, Saussoy P, Van Langendonckt A, Amorim C, Donnez J. Reimplantation of cryopreserved ovarian tissue from patients with acute lymphoblastic leukemia is potentially unsafe. Blood. 2010;116(16):2908-14.

5. Rodgers RJ, Irving-Rodgers HF, Russell DL. Extracellular matrix of the developing ovarian follicle. Reproduction. 2003;126(4):415-24.

6. Figueiredo JR, Hulshof SC, Van den Hurk R, Ectors FJ, Fontes RS, Nusgens B, et al. Development of a combined new mechanical and enzymatic method for the isolation of intact preantral follicles from fetal, calf and adult bovine ovaries. Theriogenology. 1993;40(4):789-99.

7. AbirR, Franks S, Mobberley MA, Moore PA, Margara RA, Winston RM. Mechanical isolation and in vitro growth of preantral and small antral human follicles. Fertil Steril. 1997;68(4):682-8.

8. Hovatta O, Wright C, Krausz T, Hardy K, Winston RM. Human primordial, primary and secondary ovarian follicles in long-term culture: effect of partial isolation. Hum Reprod. 1999;14(10):2519-24.

9. Martinez-Madrid B, Dolmans MM, Langendonckt AV, Defrère S, Van Eyck AS, Donnez J. Ficoll density gradient method for recovery of isolated human ovarian primordial follicles. Fertil Steril. 
2004;82(6):1648-53.

10. Dong FL, Ma L, Shi SL, Dai SJ, Liu XG, Su YC, et al. An research on the isolation methods of frozenthawed human ovarian preantral follicles. Int J Clin Exp Med. 2014;7(8):2298-303.

11. Dolmans MM, Michaux N, Camboni A, Martinez-Madrid B, Van Langendonckt A, Nottola SA, et al. Evaluation of Liberase, a purified enzyme blend, for the isolation of human primordial and primary ovarian follicles. Hum Reprod. 2006;21(2):413-20.

12. Vanacker J, Camboni A, Dath C, Van Langendonckt A, Dolmans MM, Donnez J, et al. Enzymatic isolation of human primordial and primary ovarian follicles with Liberase $\mathrm{DH}$ : protocol for application in a clinical setting. Fertil Steril. 2011;96(2):379-83.e3.

13. White SA, Djaballah H, Hughes DP, Roberts DL, Contractor HH, Pathak S, et al. A preliminary study of the activation of endogenous pancreatic exocrine enzymes during automated porcine islet isolation. Cell Transplant. 1999;8(3):265-76.

14. Wolters $\mathrm{GH}$, van Suylichem PT, van Deijnen $\mathrm{JH}$, van Schilfgaarde R. Factors influencing the isolation process of islets of Langerhans. Horm Metab Res Suppl. 1990;25:20-6.

15. Wang W, Upshaw L, Zhang G, Strong DM, Reems JA. Adjustment of digestion enzyme composition improves islet isolation outcome from marginal grade human donor pancreata. Cell Tissue Bank. 2007;8(3):187-94.

16. Telfer E, Torrance C, Gosden RG. Morphological study of cultured preantral ovarian follicles of mice after transplantation under the kidney capsule. J Reprod Fertil. 1990;89(2):565-71.

17. Xu M, Kreeger PK, Shea LD, Woodruff TK. Tissue-engineered follicles produce live, fertile offspring. Tissue Eng. 2006;12(10):2739-46.

18. Wang TR, Yan J, Lu CL, Xia X, Yin TL, Zhi X, et al. Human single follicle growth in vitro from cryopreserved ovarian tissue after slow freezing or vitrification. Hum Reprod. 2016;31(4):763-73.

19. Schmidt VM, Isachenko V, Rappl G, Rahimi G, Hanstein B, Morgenstern B, et al. Comparison of the enzymatic efficiency of Liberase TM and tumor dissociation enzyme: effect on the viability of cells digested from fresh and cryopreserved human ovarian cortex. Reprod Biol Endocrinol. 2018;16(1):57.

20. Kurbacher CM, Cree IA, Bruckner HW, Brenne U, Kurbacher JA, Müller K, et al. Use of an ex vivo ATP luminescence assay to direct chemotherapy for recurrent ovarian cancer. Anticancer Drugs. 1998;9(1):51-7.

21. Andreotti PE, Cree IA, Kurbacher CM, Hartmann DM, Linder D, Harel G, et al. Chemosensitivity testing of human tumors using a microplate adenosine triphosphate luminescence assay: clinical correlation for cisplatin resistance of ovarian carcinoma. Cancer Res. 1995;55(22):5276-82.

22. Schmidt VM, Isachenko E, Rappl G, Rahimi G, Hanstein B, Morgenstern B, et al. Construction of human artificial ovary from cryopreserved ovarian tissue: Appearance of apoptosis and necrosis after enzymatic isolation of follicles. Cryobiology. 2018;84:10-4.

23. Isachenko V, Todorov P, Isachenko E, Rahimi G, Hanstein B, Salama M, et al. Cryopreservation and xenografting of human ovarian fragments: medulla decreases the phosphatidylserine translocation rate. Reprod Biol Endocrinol. 2016;14(1):79. 
24. Wiweko B, Soebijanto S, Boediono A, Mansyur M, Siregar NC, Suryandari DA, et al. Survival of isolated human preantral follicles after vitrification: Analyses of morphology and Fas ligand and caspase-3 mRNA expression. Clin Exp Reprod Med. 2019;46(4):152-65.

25. Chiti MC, Dolmans MM, Hobeika M, Cernogoraz A, Donnez J, Amorim CA. A modified and tailored human follicle isolation procedure improves follicle recovery and survival. $\mathrm{J}$ Ovarian Res. 2017;10(1):71.

26. Lierman S, Tilleman K, Cornelissen M, De Vos WH, Weyers S, T'Sjoen G, et al. Follicles of various maturation stages react differently to enzymatic isolation: a comparison of different isolation protocols. Reprod Biomed Online. 2015;30(2):181-90.

27. Mouloungui $E$, Zver T, Roux C, Amiot $C$. A protocol to isolate and qualify purified human preantral follicles in cases of acute leukemia, for future clinical applications. J Ovarian Res. 2018;11(1):4.

28. Chambers EL, Gosden RG, Yap C, Picton HM. In situ identification of follicles in ovarian cortex as a tool for quantifying follicle density, viability and developmental potential in strategies to preserve female fertility. Hum Reprod. 2010;25(10):2559-68.

29. Nemes Z, Dietz R, Lüth JB, Gomba S, Hackenthal E, Gross F. The pharmacological relevance of vital staining with neutral red. Experientia. 1979;35(11):1475-6.

30. Repetto G, del Peso A, Zurita JL. Neutral red uptake assay for the estimation of cell viability/cytotoxicity. Nat Protoc. 2008;3(7):1125-31.

31. Lucci CM, Amorim CA, Báo SN, Figueiredo JR, Rodrigues AP, Silva JR, et al. Effect of the interval of serial sections of ovarian tissue in the tissue chopper on the number of isolated caprine preantral follicles. Anim Reprod Sci. 1999;56(1):39-49.

32. Fattahi A, Liverani L, Dittrich R, Hoffmann I, Boccaccini AR, Beckmann MW, et al. Optimization of Porcine Ovarian Follicle Isolation Methods for Better Developmental Potential. Tissue Eng Part A. 2020;26(13-14):712-9.

33. Jahr H, Pfeiffer G, Hering BJ, Federlin K, Bretzel RG. Endotoxin-mediated activation of cytokine production in human PBMCs by collagenase and Ficoll. J Mol Med (Berl). 1999;77(1):118-20.

34. Berney T, Molano RD, Cattan P, Pileggi A, Vizzardelli C, Oliver R, et al. Endotoxin-mediated delayed islet graft function is associated with increased intra-islet cytokine production and islet cell apoptosis. Transplantation. 2001;71(1):125-32.

35. Ray PD, Huang BW, Tsuji Y. Reactive oxygen species (ROS) homeostasis and redox regulation in cellular signaling. Cell Signal. 2012;24(5):981-90.

36. Hildeman DA, Mitchell T, Kappler J, Marrack P. T cell apoptosis and reactive oxygen species. J Clin Invest. 2003;111(5):575-81.

37. Circu ML, Aw TY. Reactive oxygen species, cellular redox systems, and apoptosis. Free Radic Biol Med. 2010;48(6):749-62.

38. Hatami S, Zavareh S, Salehnia M, Lashkarbolouki T, Karimi I. Comparison of oxidative status of mouse pre-antral follicles derived from vitrified whole ovarian tissue and vitrified pre-antral follicles in the presence of alpha lipoic acid. J Obstet Gynaecol Res. 2014;40(6):1680-8. 
39. Wang LY, Wang DH, Zou XY, Xu CM. Mitochondrial functions on oocytes and preimplantation embryos. J Zhejiang Univ Sci B. 2009;10(7):483-92.

40. Ramalho-Santos J, Varum S, Amaral S, Mota PC, Sousa AP, Amaral A. Mitochondrial functionality in reproduction: from gonads and gametes to embryos and embryonic stem cells. Hum Reprod Update. 2009;15(5):553-72.

41. Tirmenstein MA, Nicholls-Grzemski FA, Schmittgen TD, Zakrajsek BA, Fariss MW. Characterization of nitric oxide production following isolation of rat hepatocytes. Toxicol Sci. 2000;53(1):56-62.

42. Sergent O, Griffon B, Morel I, Chevanne M, Dubos MP, Cillard P, et al. Effect of nitric oxide on ironmediated oxidative stress in primary rat hepatocyte culture. Hepatology. 1997;25(1):122-7.

43. Förstermann U, Kleinert H. Nitric oxide synthase: expression and expressional control of the three isoforms. Naunyn Schmiedebergs Arch Pharmacol. 1995;352(4):351-64.

44. Heeren AM, van Iperen L, Klootwijk DB, de Melo Bernardo A, Roost MS, Gomes Fernandes MM, et al. Development of the follicular basement membrane during human gametogenesis and early folliculogenesis. BMC Dev Biol. 2015;15:4.

45. Stenn KS, Link R, Moellmann G, Madri J, Kuklinska E. Dispase, a neutral protease from Bacillus polymyxa, is a powerful fibronectinase and type IV collagenase. J Invest Dermatol. 1989;93(2):28790.

46. Oktay K, Nugent D, Newton H, Salha O, Chatterjee P, Gosden RG. Isolation and characterization of primordial follicles from fresh and cryopreserved human ovarian tissue. Fertil Steril. 1997;67(3):4816.

47. Yin H, Kristensen SG, Jiang H, Rasmussen A, Andersen CY. Survival and growth of isolated pre-antral follicles from human ovarian medulla tissue during long-term 3D culture. Hum Reprod. 2016;31(7):1531-9.

48. Isachenko V, Morgenstern B, Todorov P, Isachenko E, Mallmann P, Hanstein B, et al. Patient with ovarian insufficiency: baby born after anticancer therapy and re-transplantation of cryopreserved ovarian tissue. Journal of Ovarian Research. 2020;13(1):118.

49. Abir R, Fisch B, Nitke S, Okon E, Raz A, Ben Rafael Z. Morphological study of fully and partially isolated early human follicles. Fertil Steril. 2001;75(1):141-6.

50. Nicolantonio FD. Multidrug resistance in solid tumours. 2004.

51. Fortune JE. The early stages of follicular development: activation of primordial follicles and growth of preantral follicles. Anim Reprod Sci. 2003;78(3-4):135-63.

52. Gougeon A. Regulation of ovarian follicular development in primates: facts and hypotheses. Endocr Rev. 1996;17(2):121-55.

53. Cortvrindt RG, Smitz JE. Fluorescent probes allow rapid and precise recording of follicle density and staging in human ovarian cortical biopsy samples. Fertil Steril. 2001;75(3):588-93.

54. Korkmaz F, Malama E, Siuda M, Leiding C, Bollwein H. Effects of sodium pyruvate on viability, synthesis of reactive oxygen species, lipid peroxidation and DNA integrity of cryopreserved bovine 
sperm. Anim Reprod Sci. 2017;185:18-27.

55. Amorim CA, Van Langendonckt A, David A, Dolmans MM, Donnez J. Survival of human pre-antral follicles after cryopreservation of ovarian tissue, follicular isolation and in vitro culture in a calcium alginate matrix. Hum Reprod. 2009;24(1):92-9.

\section{Figures}

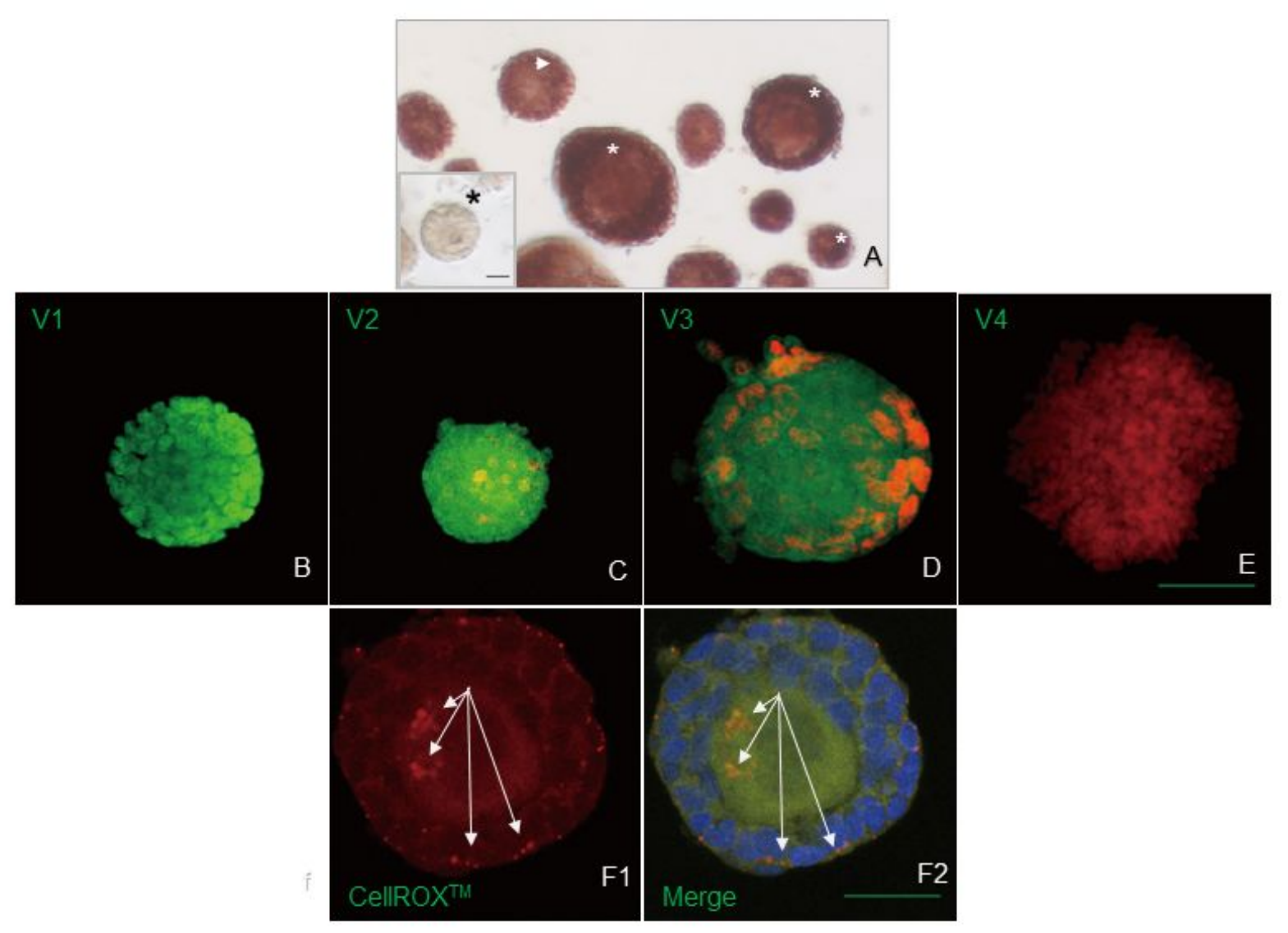

\section{Figure 1}

Example of isolated follicles treated with a neutral red viability dye and life/dead fluorochrome assay. A Follicle viability assessment with neutral red viability dye which shows a deep red color in acid cell structures like lysosomes. White asterisk - deep red stained follicles; white arrows head - light-red stained follicles; dark asterisk - non-stained follicles. Bar scale $=50 \mu \mathrm{m}$. B - V1, the completely viable follicle (both as well granulosa cells, as oocyte show bright green fluorescence) positive to Calcein AM and negative to Ethidium Homodimer-1; C - V2, minimally damaged follicle with $<10 \%$ of dead GC positive (bright red color) to Ethidium Homodimer-1; D - V3, moderately damaged follicle with $10-50 \%$ of dead follicular cells; E - V4, dead follicle with bright red fluorescence (positive to Ethidium Homodimer-1, negative to Calcein AM); F1 - follicle after incubation with CellROX® Deep Red Reagent shows the 
presence of deep red on reactive oxygen species (white arrows); F2 - the same stained with CellROX® Deep Red Reagent follicle after contra staining with a tubulin and DAPI. Scale bar $=20 \mu \mathrm{m}$.
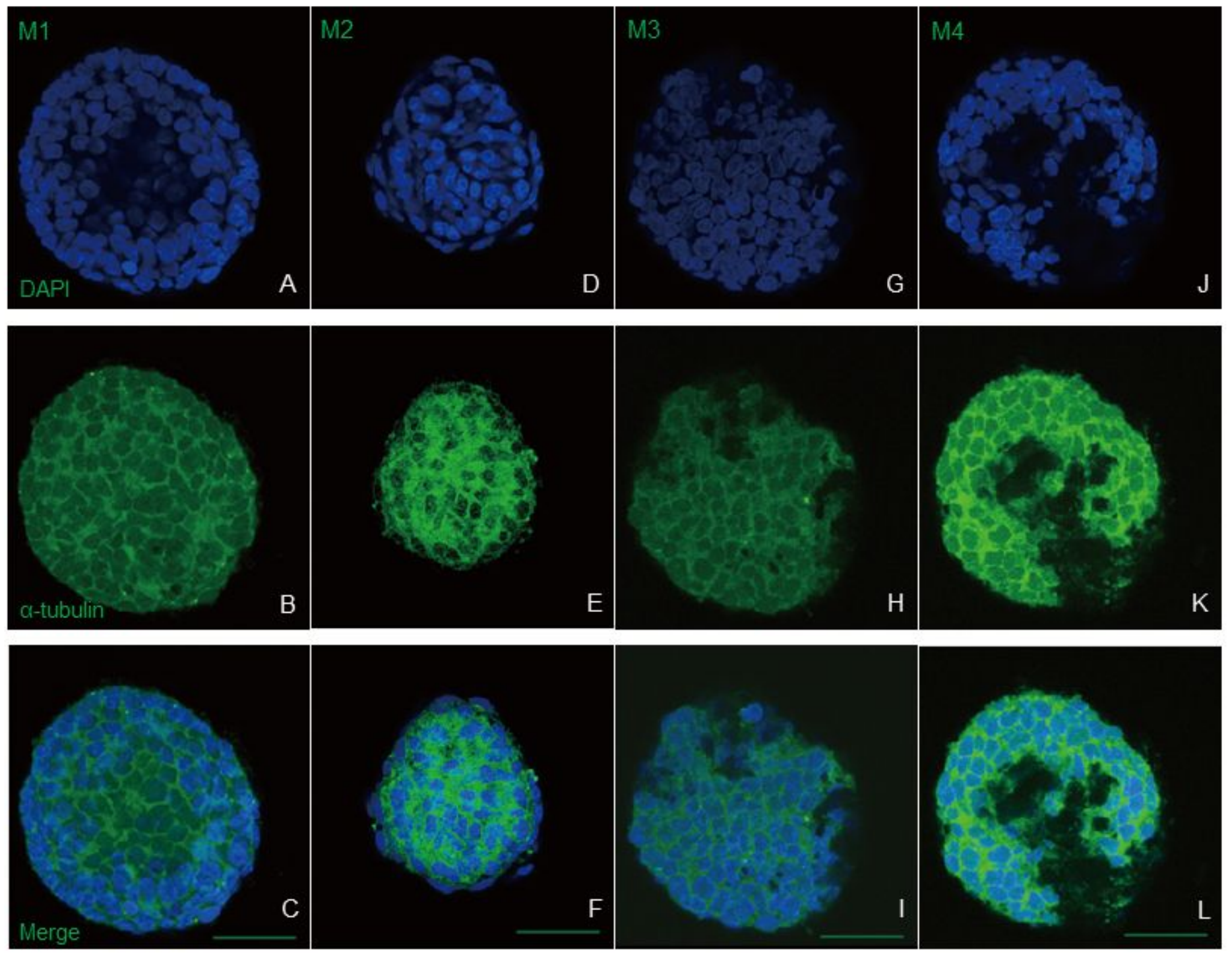

\section{Figure 2}

Example of morphological grading of isolated follicles using fluorescence dye. M1 (A - C) - spherical form with a complete granulosa cell layer. $M 2(D-F)$ - irregular form with complete granulosa cell layer. M3 (G - I) - irregular form with <10\% granulosa cell loss. M4 (J - L) - total atypical form with 10-50\% granulosa cell loss. A - J - a typical example of follicles from different morphological groups stained by DAPI show deep blue fluorescence of DNA of follicular cells; B - K - a typical example of follicles from different morphological groups stained by anti-a-tubulin antibody produce green fluorescence of contrasted cytoskeletal a-tubulin; C - L - a typical example of follicles from different morphological groups after merge stained with DAPI and anti-a-tubulin antibody. Scale bar $=20 \mu \mathrm{m}$. 

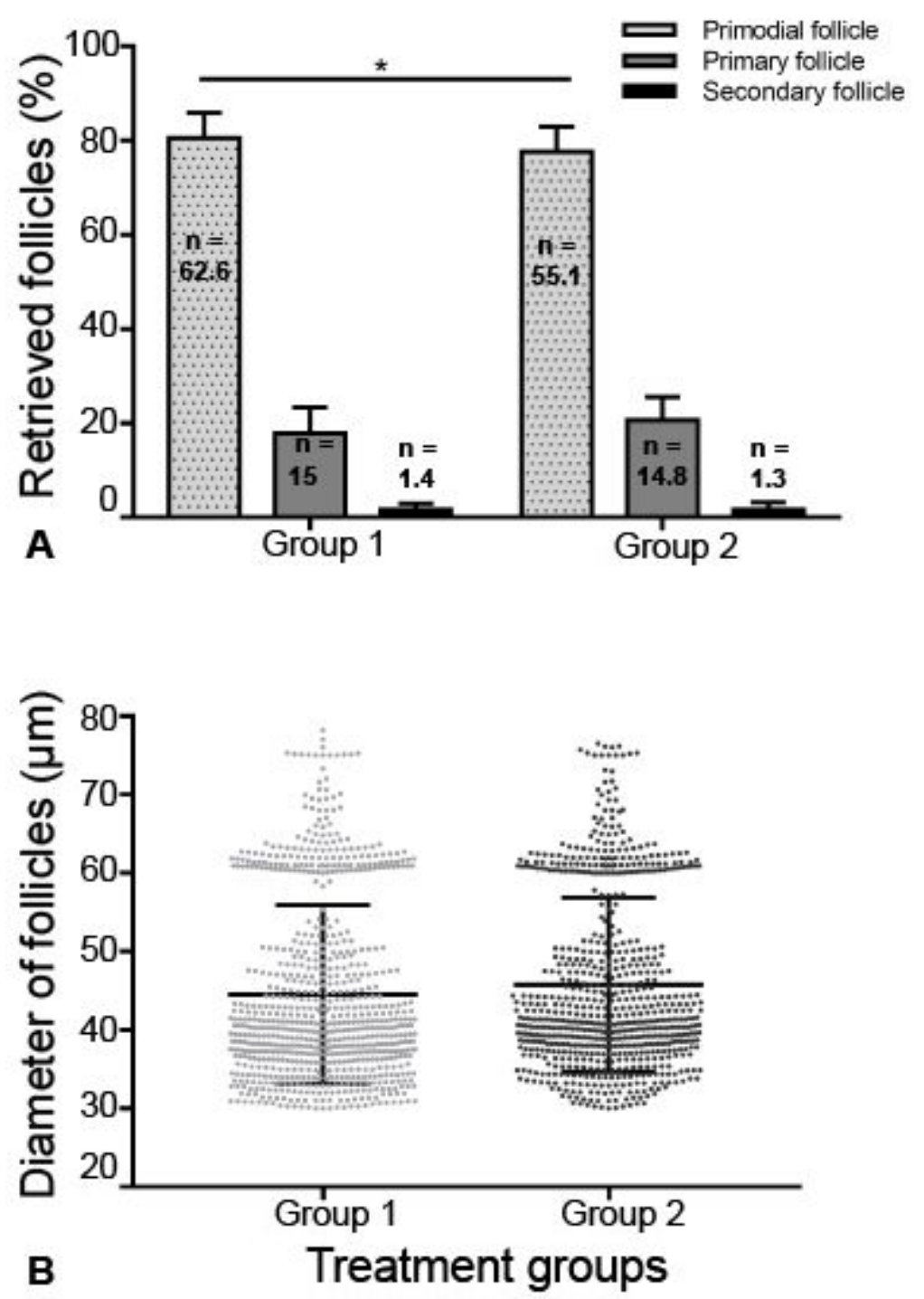

Figure 3

The distribution of follicles according to their diameter and maturity in each treatment group. A - Rate of retrieved follicles of different maturity inside of each treatment group. Mean number of retrieved follicles of different maturity inside of each treatment group. B - Distribution of follicles according to their diameter in both treatment groups. Significance of results are presented as mean $\pm S D ;{ }^{*} p<0.05$. 
Follicle stained with neutral red

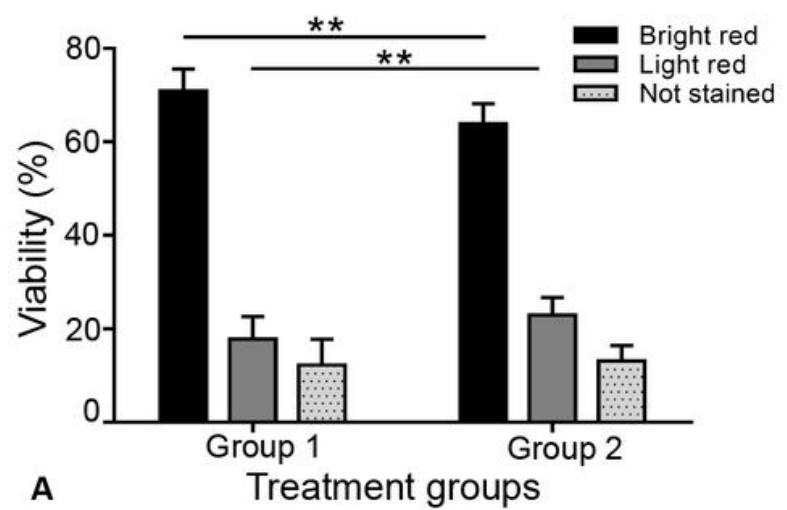

Follicle stained with calcein AM \& ethidium homodimer-1

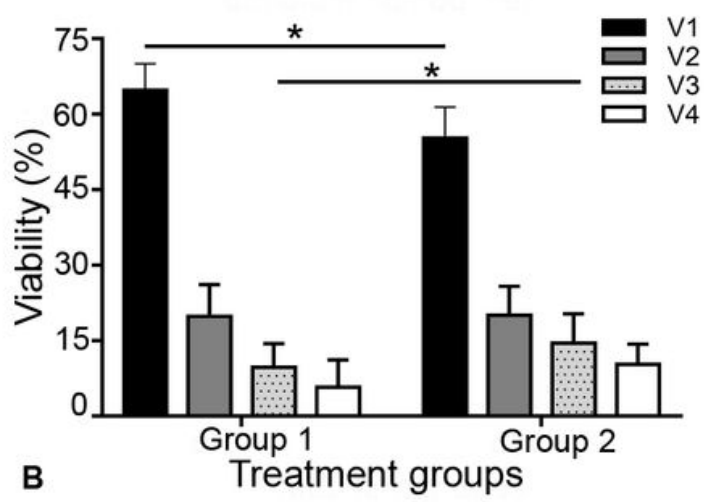

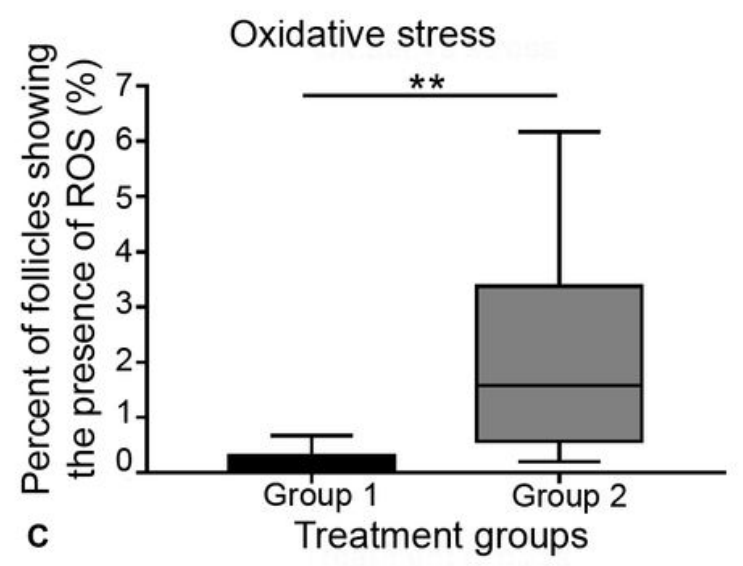

Figure 4

Viability assessment of isolated follicles depending on the type of enzymatic treatment of ovarian cortex. A - viability of follicles stained with neutral red in different treatment groups. B - viability of follicles stained with Calcein AM and ethidium homodimer-1 in different treatment groups. C - assessment of oxidative stress in cells of follicles using ROS assay in different treatment groups. Significance of results are presented as mean $\pm S D ;{ }^{*} p<0.05,{ }^{* *} p<0.01$. 


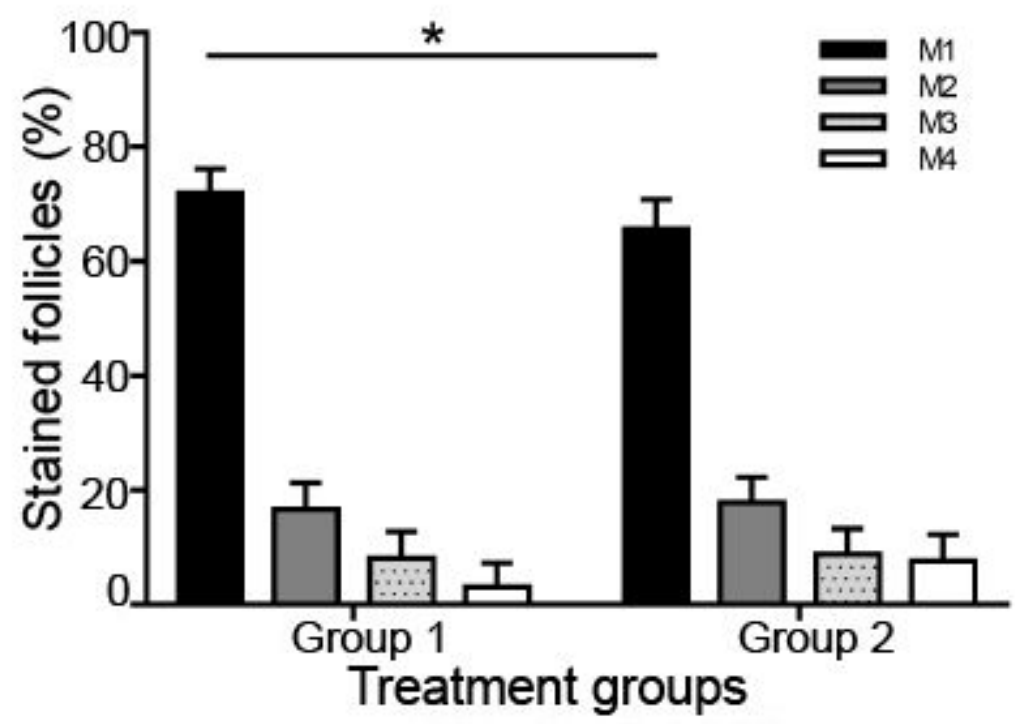

\section{Figure 5}

Morphology assessment of retrieved follicles depending on the type of enzymatic treatment of ovarian cortex. Morphology assessment of retrieved follicles depending on the type of enzymatic treatment of ovarian cortex using nuclear stain DAPI with fluorescence contrasting of cytoskeletal a-tubulin. Significance of results are presented as mean $\pm S D$; $* p<0.05$, $* * p<0.01$.
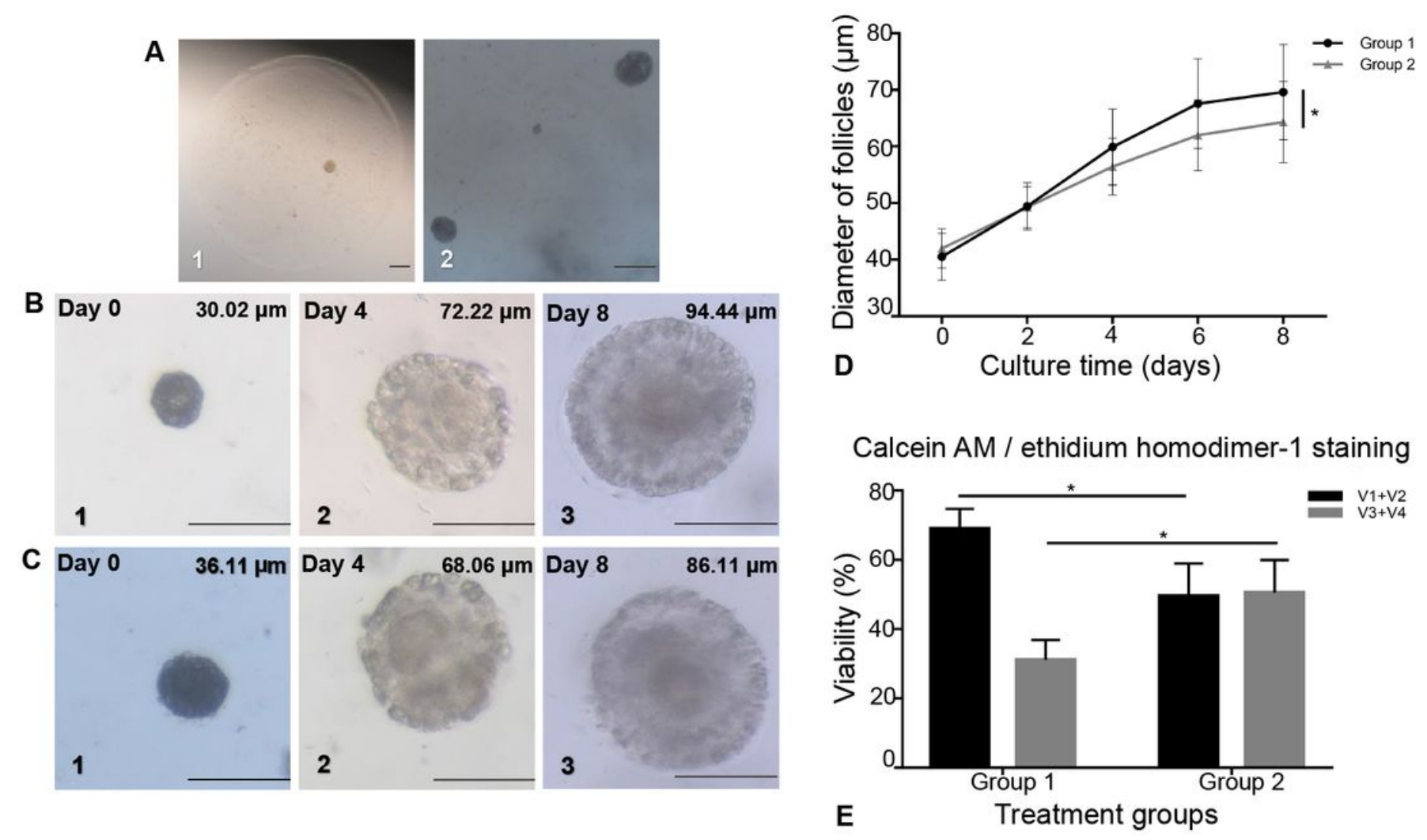


\section{Figure 6}

Growth and viability of isolated follicles during in vitro culture. Growth and viability of isolated and embedded in alginate gel capsule follicles during in vitro culture depending on the type of enzymatic treatment of ovarian cortex. A1 - 3 - typical view of embedded in alginate gel capsule follicles; B1 - 3 typical view of follicles after enzymatic treatment with TDE (Group 1) culture in alginate gel capsule; $\mathrm{C} 1$ 3 - typical view of follicles after enzymatic treatment with Liberase DH in combination with DNase (Group 2) culture in alginate gel capsule; Scale bar $=50 \mu \mathrm{m}$. D - Changing of the diameter of follicles embedded in alginate gel and cultured in vitro for 8 days depending on the type of enzymatic treatment of ovarian. Significance of results are presented as mean $\pm S D ;{ }^{*} p<0.05$, ${ }^{*} p<0.01$. E - Viability assessment of isolated follicles embedded in alginate gel and cultured in vitro for 8 days depending on the type of enzymatic treatment of ovarian cortex using fluorescence vitality dyes Calcein AM and ethidium homodimer-1. Class V1 + V2 represented viable follicles and Class V3 and V4 represented non-viable follicles. Significance of results are presented as mean $\pm S D ;{ }^{\star} p<0.05$. Group $1-$ follicles isolated from ovarian cortex using TDE; Group 2 - follicles isolated from ovarian cortex using Liberase DH in combination with DNase. 